\title{
Effect of Intake of Dried Mackerel on Brain Fatty Acid Composition and Passive Avoidance Performance
}

\author{
Sun-Young Lim $^{1, *}$ and Hyung-Ju Choi
}

\author{
Division of Marine Environment \& Bioscience, Korea Maritime University, Busan, Korea
}

\begin{abstract}
This study attempts to determine the effect of feeding mackerel dried by low temperature vacuum method to mice on their learning behavior and fatty acid composition of the nervous system. Thirty-two male mice were fed either a control (palm oil, control group) diet or a diet of $20 \%$ dried mackerel (mackerel group) for three months. Learning behavior was assessed using a passive avoidance test, and the tissue fatty acid composition was measured after the behavioral test. The lack of experience with electronic foot shocks resulted in both the control and mackerel groups showing shorter latency during the acquisition trial (Day 1). The avoidance latencies of each group subsequently increased after multiple acquisition trials. The mackerel group showed a significantly longer avoidance latency on day 2 than was the case with the control group $(\mathrm{p}<0.05)$. In terms of the fatty acid composition of the serum and nervous tissues such as the brain and retina, the mackerel group showed increased percentages of total n-3 fatty acids, and especially docosahexaenoic (DHA) and eicosapentaenoic (EPA) acids. Meanwhile, the control group showed decreased DHA levels, but increased docosapentaenoic acid (DPAn-6) levels. From the above results, it may be concluded that the intake of mackerel dried by low temperature vacuum improved learning behavior, as assessed by passive avoidance test, with increased DHA in the brain.
\end{abstract}

Key Words: Brain, mackerel, fatty acid composition, n-3 fatty acid deficiency, passive avoidance test.

\section{INTRODUCTION}

The consumption of fish is known to have many health benefits. This is due, in part, to high concentrations of $n-3$ polyunsaturated fatty acids (PUFAs) including docosaheaenoic (DHA, 22:6n-3) and eicosapentaenoic (EPA, 20:5n-3) acids. Some of the benefits of fish can be obtained by consuming fish oil extracts. Several studies in adults have suggested that fish intake reduces various cardiovascular risk factors through such means as the improvement of lipid profiles, the inhibition of lipid peroxidation, and the reduction of platelet aggregation. In addition, fish is also known to have an anti-arrhythmic effect [1-2]. Siscovick et al. [3] have suggested that the effect of fish consumption in terms of the prevention of strokes is mediated by the cell membrane concentrations of the PUFAs. While some studies have shown substantial benefits emanating from fish consumption, others have been for the most part negative. A study conducted by Kromhout et al. [4] found a lower instance of deaths related to coronary heart disease amongst those who ate fish. Ascherio et al. [2] suggested that while fish consumption was beneficial in conjunction with some endpoints such as fatal and non-fatal coronary heart disease, myocardial infarction, and stroke, it showed no benefits in terms of the prevention of cardiac bypass surgery. Meanwhile, Caicoya [5] reported that increased fish consumption actually entailed a greater risk of stroke.

While the benefits of fish consumption are attributable to higher concentrations of PUFAs, the most beneficial PUFAs

*Address correspondence to this author at the Division of Marine Environment \& Bioscience, Korea Maritime University, Busan, Korea; Tel: +82-51410-4757; Fax: +82-51-404-3988; Email: sylim@hhu.ac.kr are DHA and to a lesser extent EPA [6]. DHA is an essential component for maintaining and improving brain functions in animals that is transported across the placenta and delivered in postnatal milk. Postnatal DHA has been positively associated with visual and language development in breast-fed infants. Helland et al. [7] showed that cod liver oil supplements improved children's IQ at 4 years of age. In the present experiment, our purpose was to examine the effect of the intake of dried mackerel, which was enriched with DHA and EPA so as to increase the intake of such n-3 PUFAs, on passive avoidance learning task. The passive avoidance task is considered to be a simple test of leaning and memory in normal mice. A low temperature vacuum dryer was employed to dry the mackerel in a manner which would make it possible to minimize nutritional deterioration. The relationship between learning behavior and brain fatty acid composition was also investigated using adult mice fed with either an n-3 fatty acid deficient diet or mackerel supplements.

\section{MATERIALS AND METHODS}

\section{Animals and Diets}

Male Crj: CD-1 mice 4 weeks of age were obtained from Charles River Japan Inc. (Atsugi, Kanagawa, Japan). Thirtytwo mice were randomly divided into 2 groups of sixteen. These included a control group that was fed a palm oil diet (Control group) and another group that was fed a $20 \%$ dried mackerel diet (Mackerel group) (Table 1) and mice were fed on these diets for three months. The macronutrients, including carbohydrates, protein and lipids, were adjusted in accordance with the amount of mackerel. Mackerel (Scomber japonicus) obtained from South Sea, Korea was dried under 40 torr at $40^{\circ} \mathrm{C}$ using low temperature vacuum drying system. The dried mackerel contained $33.17 \%$ crude 
fat, $59.69 \%$ crude protein and $0.43 \%$ crude carbohydrates. The main fatty acid composition of the lipids in each diet group is presented in Table 1. The custom pelleted diets were commercially obtained, and a cold pelleting process was employed to preserve unsaturated fats (Dooyeul Biotec, Seoul, Korea). In the present study, the control diet was n-3 fatty acid deficient diet with deficient in $\alpha$-linolenic acid and DHA. The diets were stored at $-25^{\circ} \mathrm{C}$, and fresh supplies were given to the mice once every two days. The diet and water were given ad libitum. Body weights were measured once a week. All mice were housed in a standard environment in which the temperature was maintained at $23 \pm 1^{\circ} \mathrm{C}$, and relative humidity was kept at $65 \pm 5 \%$ with $12 \mathrm{~h}$ periods of light and darkness. This experimental protocol was approved by Korea Maritime University's Animal Care and Use Committee.

Table 1. The Composition of Diet Experimental Diets

\begin{tabular}{|c|c|c|}
\hline \multirow[t]{2}{*}{ Ingredients } & \multicolumn{2}{|c|}{ Diet Group (g/kg) } \\
\hline & Control & Mackerel \\
\hline Corn starch & 436 & 421 \\
\hline Casein & 200 & 81 \\
\hline Sucrose & 150 & 150 \\
\hline Cellulose & 50 & 50 \\
\hline Vitamin mixture $^{\mathrm{a}}$ & 40 & 40 \\
\hline Mineral mixture $^{\mathrm{b}}$ & 20 & 20 \\
\hline L-Methionine & 2 & 2 \\
\hline Choline chloride & 2 & 2 \\
\hline Palm oil & 100 & 34 \\
\hline Mackerel & - & 200 \\
\hline \multicolumn{3}{|c|}{ Selected Fatty acid composition } \\
\hline Total Saturates & 51.9 & 45.0 \\
\hline Total Monounsaturated & 38.3 & 28.7 \\
\hline Total n-6 fatty acids & 9.0 & 8.2 \\
\hline Total n-3 fatty acids & 0.01 & 15.6 \\
\hline $20: 5 n-3$ & - & 4.5 \\
\hline $22: 6 n-3$ & - & 8.8 \\
\hline
\end{tabular}

Control, $10 \%$ palm oil diet; Mackerel, 20\% dried mackerel diet.

${ }^{2} \mathrm{AIN}-93 \mathrm{G}$ vitamin mixture contained (in $\mathrm{g} / \mathrm{kg}$ of mixture): niacin 3; calcium pantothenate $\mathrm{HCl} 1.6$; pyridoxine $\mathrm{HCl} 0.7$; thiamine $\mathrm{HCl} 0.6$; riboflavin 0.6 ; folic acid 0.2 ; biotin 0.02 ; vitamin $\mathrm{E}$ acetate $(500 \mathrm{IU} / \mathrm{g}) 15$; vitamin $\mathrm{B}_{12}(0.1 \%) 2.5$; vitamin A palmitate $(500,000 \mathrm{IU} / \mathrm{g}) 0.8$; vitamin $\mathrm{D}_{3}(400,000 \mathrm{IU} / \mathrm{g}) 0.25$; vitamin $\mathrm{K} 1 /$ dextrose mixtures $(10 \mathrm{mg} / \mathrm{g}) 7.5$; sucrose 967.23 .

${ }^{b} \mathrm{AIN}-93 \mathrm{G}$ mineral mixture contained (in $\mathrm{g} / \mathrm{kg}$ of mixture): calcium carbonate 357 ; potassium phosphate (monobasic) 196; potassium citrate $\mathrm{H}_{2} \mathrm{O} 70.78$; sodium chloride 74; potassium sulfate 46.6; magnesium oxide 24; ferric citrate, USP 6.06; zinc carbonate 1.65 ; manganous carbonate 0.63 ; cupric carbonate 0.3 ; potassium iodate 0.01 ; sodium selenate 0.01025 ; ammonium paramolybdate $4 \mathrm{H}_{2} \mathrm{O} 0.00795$; sodium metasilicate $9 \mathrm{H}_{2} \mathrm{O} 1.45$; chromium potassium sulfate $12 \mathrm{H}_{2} \mathrm{O} 0.275$; lithium chloride 0.0174 ; boric acid 0.0815 ; sodium flouride 0.0635 ; nickel carbonate 0.0318 ; ammonium vanadate 0.0066 ; sucrose finely powdered 221.026 .

\section{Passive Avoidance Test}

When mice were 15 weeks old, passive avoidance test was performed. A step-through passive avoidance apparatus [8] (Gemini Avoidance System, San Diego Instruments Inc.,
San Diego, USA) was employed to evaluate learning and memory abilities. The box consisted of two compartments of equal size $(17 \times 12 \times 11 \mathrm{~cm})$ separated by a common wall. 20 $\mathrm{W}$ bulbs were used to brightly illuminate one of the two compartments from above. The other compartment was not illuminated and had an electrifiable grid floor. A guillotine type door $(6 \times 6 \mathrm{~cm})$ was located in the center of the common wall to allow the mice to move about freely between the compartments. The door was then closed and the mice were placed in their respective compartments. After a $60 \mathrm{~s}$ adaptation period, the compartment lit up and the door opened. Once a mouse entered the dark compartment, the door closed and an electric foot shock of $0.4 \mathrm{~mA}$ was delivered for $1 \mathrm{sec}$. Each mouse underwent one trial, and was assigned a cut-off time of $300 \mathrm{~s}$. The initial latency time required to enter the dark chamber was then recorded. After $24 \mathrm{~h}$, the latency time was measured in the same manner as during the acquisition trial, and was tested on consecutive days.

\section{Measurement of Lipid Composition}

After the behavioral experiment, the mice were then decapitated. Tissue samples that included those from the brain and retina were removed and stored at $-80^{\circ} \mathrm{C}$. The lipids extracted from the tissues were prepared in accordance with the method developed by Folch et al. [9]. The lipid extracts were then transmethylated with $14 \% \mathrm{BF}_{3}$-methanol at $100^{\circ} \mathrm{C}$ for 60 min using a modified version of the method employed by Morrison and Smith [10] that involved the addition of hexane. Gas liquid chromatography using a $100 \mathrm{~m} \times 0.25 \mathrm{~mm}$ i.d. $\times 0.2 \mu \mathrm{m}$ capillary column (SP-2560, Supelco, Bellefonte, USA) was employed to separate the fatty acid methyl esters, and the latter were detected through flame ionization [11]. The detector and injector temperatures were set to $250^{\circ} \mathrm{C}$. The oven temperature program began at $130^{\circ} \mathrm{C}$ and increased to $175^{\circ} \mathrm{C}$ at $4{ }^{\circ} \mathrm{C} / \mathrm{min}$, then increased at $1{ }^{\circ} \mathrm{C} / \mathrm{min}$ to $210^{\circ} \mathrm{C}$, and finally increased at $30^{\circ} \mathrm{C} / \mathrm{min}$ to $245^{\circ} \mathrm{C}$, with a final hold for $15 \mathrm{~min}$. The chromatograms were recorded and the percentage composition of individual peaks was calculated with a VARIAN CP-3380 (Varian Inc., CA, USA). The fatty acid methyl esters were identified through a comparison with the retention times obtained using a standard mixture (37 Component FAME Mix, Supelco, Bellefonte, USA). The percentages of individual and total fatty acids were obtained using an internal standard (22:3n-3 as methyl ester).

\section{Statistics}

All results were expressed as means \pm the standard error of the mean (SEM), with statistical significance determined by t-test using the SIGMASTAT statistical program package (Jandel Co., Erkrath, Germany).

\section{RESULTS AND DISCUSSION}

\section{Fatty Acid Composition of Serum, Brain, and Retina}

A difference in the mean percentage of both the DHA and docosapentaenoic acid (DPAn-6, 22:5n-6) fatty acids found in the serum of the two dietary groups was uncovered (Table 2). The mice fed with a mackerel diet exhibited higher levels of DHA and EPA than the control group. Meanwhile, the mice in the control group exhibited lower levels of DHA and total n-3 fatty acids than did the mackerel diet group, but higher percentages of DPAn- 6 and total $n-6$ fatty acids than the latter $(\mathrm{p}<0.05)$. Moreover, the mackerel 
group was found to have higher percentages of total saturated fatty acids and lower total monounsaturated fatty acids than was the case with the control group $(\mathrm{p}<0.05)$.

Table 2. Effect of Dried Mackerel Feeding on Serum Fatty Acid Composition (wt \%) in Mice

\begin{tabular}{|c|c|c|}
\hline \multirow{2}{*}{ Fatty Acids } & \multicolumn{2}{|c|}{ Dietary Group } \\
\cline { 2 - 3 } & Control & Mackerel \\
\hline \hline Total Saturates & $31.0 \pm 0.53$ & $35.3 \pm 1.41^{*}$ \\
\hline Total Monounsaturated & $31.7 \pm 2.11$ & $15.1 \pm 1.41^{*}$ \\
\hline $18: 2 \mathrm{n}-6$ & $11.1 \pm 1.02$ & $9.2 \pm 0.44$ \\
\hline $20: 3 \mathrm{n}-6$ & $1.6 \pm 0.10$ & $0.3 \pm 0.03^{*}$ \\
\hline $20: 4 \mathrm{n}-6$ & $9.0 \pm 0.91$ & $8.1 \pm 0.58$ \\
\hline $22: 5 \mathrm{n}-6$ & $1.1 \pm 0.18$ & $0.2 \pm 0.02^{*}$ \\
\hline Total n-6 & $23.3 \pm 1.50$ & $18.3 \pm 0.62^{*}$ \\
\hline $18: 3 \mathrm{n}-3$ & $0.4 \pm 0.05$ & $0.3 \pm 0.03$ \\
\hline $20: 5 \mathrm{n}-3$ & $0.1 \pm 0.02$ & $5.0 \pm 0.30^{*}$ \\
\hline $22: 6 \mathrm{n}-3$ & $1.0 \pm 0.09$ & $13.7 \pm 0.21^{*}$ \\
\hline Total n-3 & $1.6 \pm 0.08$ & $19.0 \pm 0.27^{*}$ \\
\hline Total Fatty Acids ( $\mathrm{nl} / \mathrm{ml} \mathrm{serum})$ & $4.7 \pm 0.81$ & $3.1 \pm 0.45$ \\
\hline
\end{tabular}

Data are mean \pm SEM values $(n=5)$.

Control, $10 \%$ palm oil diet; Mackerel, $20 \%$ dried mackerel diet. ${ }^{*} p<0.05$, versus control.

In the brain, the percentage of DHA and total n-3 fatty acids was found to be significantly higher in the mackerel diet group than in the control group (Table 3). Meanwhile, mice fed the control diet featured lower DHA levels accompanied by increased arachidonic acid (AA, 20:4n-6) and DPAn-6 levels in their total brain lipids. A pattern similar to that of brain fatty acid composition was also uncovered in the case of the retina. While the percentage of AA, DPAn-6 and total n- 6 fatty acids, and the ratio of n- 6 to n-3 was higher in the control group, the mackerel group exhibited higher percentages of 22:5n-3, DHA and total n-3 fatty acids (Table 4). No differences were uncovered between the two groups in terms of the percentages of total saturated and monounsaturated fatty acids found in both the brain and retina.

\section{Effect on Passive Avoidance Test}

No differences were uncovered between the two experimental groups in terms of body weight and food consumption. Moreover, the acquisition trial (Day 1) revealed no significant differences between the two groups with regards to the latency with which the dark room was entered (control: 22.4 \pm 17.4 ; mackerel: 9.0 \pm 1.16 ) (Fig. 1). Multiple acquisition trials were improved by the supplementation of mackerel diet (Day 2-4). Specially, the mackerel group showed a much more significant increase in avoidance latency on day 2 than the control group $(\mathrm{p}<0.05)$. No significant differences in latency were recorded between the two groups after day 2 because both groups had by then, through repeated trials, learned how to avoid the electronic shock.
Table 3. Effect of Dried Mackerel Feeding on Brain Fatty Acid Composition (wt \%) in Mice

\begin{tabular}{|c|c|c|}
\hline \multirow{2}{*}{ Fatty Acids } & \multicolumn{2}{|c|}{ Dietary Group } \\
\cline { 2 - 3 } & Control & Mackerel \\
\hline \hline Total Saturates & $42.1 \pm 2.03$ & $43.7 \pm 0.89$ \\
\hline Total Monounsaturates & $22.8 \pm 2.15$ & $23.5 \pm 0.84$ \\
\hline $18: 2 \mathrm{n}-6$ & $0.21 \pm 0.01$ & $0.19 \pm 0.01$ \\
\hline $20: 3 \mathrm{n}-6$ & $0.16 \pm 0.07$ & $0.28 \pm 0.07$ \\
\hline $20: 4 \mathrm{n}-6$ & $7.44 \pm 0.31$ & $5.38 \pm 0.12^{*}$ \\
\hline $22: 2 \mathrm{n}-6$ & $0.41 \pm 0.17$ & $0.36 \pm 0.22$ \\
\hline $22: 5 \mathrm{n}-6$ & $6.30 \pm 0.25$ & $5.21 \pm 0.23^{*}$ \\
\hline Total n-6 & $14.5 \pm 0.54$ & $11.4 \pm 0.35^{*}$ \\
\hline $22: 5 \mathrm{n}-3$ & $0.47 \pm 0.05$ & $0.82 \pm 0.08^{*}$ \\
\hline $22: 6 \mathrm{n}-3$ & $9.91 \pm 0.28$ & $13.1 \pm 0.39^{*}$ \\
\hline Total n-3 & $10.4 \pm 0.30$ & $13.9 \pm 0.44^{*}$ \\
\hline Total Fatty Acids $(\mu \mathrm{g} / \mathrm{mg}$ brain $)$ & $25.6 \pm 1.32$ & $25.7 \pm 1.72$ \\
\hline
\end{tabular}

Data are mean \pm SEM values $(n=5)$.

Control, $10 \%$ palm oil diet; Mackerel, $20 \%$ dried mackerel diet. ${ }^{*} p<0.05$, versus control.

Table 4. Effect of Dried Mackerel Feeding on Retinal Fatty Acid Composition (wt \%) in Mice

\begin{tabular}{|c|c|c|}
\hline \multirow{2}{*}{ Fatty Acids } & \multicolumn{2}{|c|}{ Dietary Group } \\
\cline { 2 - 3 } & Control & Mackerel \\
\hline \hline Total Saturates & $47.1 \pm 0.74$ & $46.7 \pm 0.60$ \\
\hline Total Monounsaturates & $18.9 \pm 1.72$ & $14.7 \pm 0.97$ \\
\hline $18: 2 \mathrm{n}-6$ & $0.90 \pm 0.14$ & $0.52 \pm 0.04^{*}$ \\
\hline $18: 3 \mathrm{n}-6$ & $0.39 \pm 0.14$ & $0.30 \pm 0.02$ \\
\hline $20: 4 \mathrm{n}-6$ & $8.80 \pm 0.57$ & $4.20 \pm 0.16^{*}$ \\
\hline $22: 5 \mathrm{n}-6$ & $2.52 \pm 0.06$ & $1.20 \pm 0.25^{*}$ \\
\hline Total n-6 & $12.6 \pm 0.45$ & $6.23 \pm 0.24^{*}$ \\
\hline $22: 5 \mathrm{n}-3$ & $0.47 \pm 0.22$ & $0.83 \pm 0.04^{*}$ \\
\hline $22: 6 \mathrm{n}-3$ & $16.8 \pm 1.31$ & $22.6 \pm 1.17^{*}$ \\
\hline Total n-3 & $17.4 \pm 1.49$ & $23.4 \pm 1.17^{*}$ \\
\hline Total Fatty Acids $(\mu \mathrm{g} / \mathrm{mg}$ retina) & $8.9 \pm 1.99$ & $7.0 \pm 0.95$ \\
\hline
\end{tabular}

Data are mean \pm SEM values $(n=5)$.

Control, $10 \%$ palm oil diet; Mackerel, $20 \%$ dried mackerel diet. ${ }^{*} p<0.05$, versus control.

From the above results, we found that mice fed with a diet of mackerel were better able to perform passive avoidance tasks than those fed an n-3 fatty acid deficient diet. The improved passive avoidance learning of the mackerel group was associated with higher levels of DHA in brain lipids. These results confirm other studies that have found an increased percentage of DHA in the brain following the provision of dietary supplements containing this fatty acid, and an improvement in mice's performance of the maze-learning 
ability test [12, 13]. Garcia-Calatayud et al. [14] demonstrated that young rats with a deficint supply of n-3 fatty acid limited to the lactation period presented poor memory retention in passive avoidance test directly correlated to DHA and inversely correlated to brain DPAn-6 levels. Both biochemical and functional consequences of this dietary deficiency were reversed when a supplement of DHA was administered to the deficient animals. This may signify that the increase in DHA and reciprocal decrease in AA and DPAn-6 that occurs within the mice's brain after the latter have been fed DHA are somehow related to improvements in learning ability. Gamoh et al. [15] have suggested that the chronic administration of DHA raised DHA percentages in the cerebrum, cerebellum, and hippocampus, and that the ratio of DHA/AA in the cerebral cortex may be considered as an indicator of learning ability. These observations are also supported by other studies in which mice fed an n-3 fatty acid deficient diet exhibited deficiencies in terms of their learning ability $[16,17]$. Another indicator of the improved learning ability of mice may very well be the fact that the deficiency of $n-3$ fatty acids induced a decrease in dopaminergic receptors in the synaptic membrane [18].

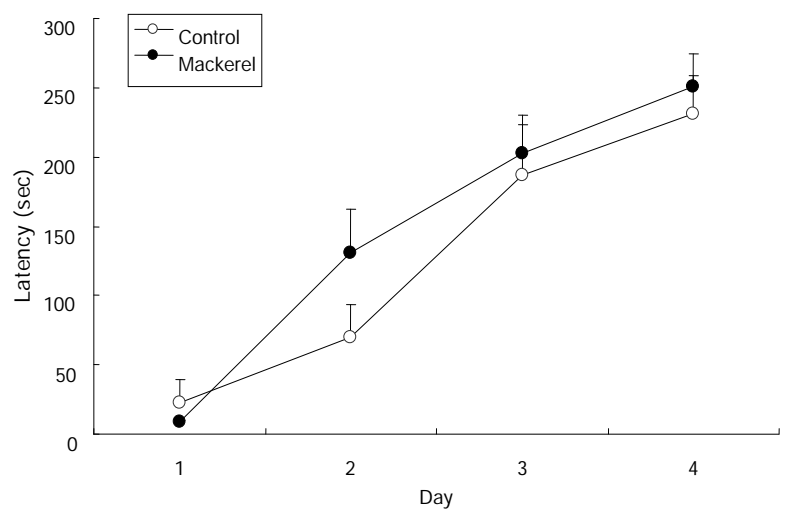

Fig. (1). Effect of dried mackerel feeding on latency in passive avoidance performance. Mice fed the control (palm oil) and mackerel diets for 3 months. Data are means \pm SEM values $(n=16)$. ${ }^{*} \mathrm{p}<$ 0.05 , versus control.

The provision of fish oil or DHA supplements has also been found to improve the elderly's performance on intelligence tests [19] and to reduce aggression in young adults [20]. Studies conducted on humans have shown that the intake of fish may delay the onset Alzheimer's disease, and also that a lower incident of depression was uncovered in patients who regularly consumed fish [21,22]. A recent study using an Alzheimer mouse model found that the intake of DHA inhibits the synthesis of amyloid precursor protein, thereby suggesting that fish oil may also help prevent or delay the progression of Alzheimer's disease [23]. Thus, fish consumption may be beneficial to brain function.

In summary, the passive avoidance test conducted as part of this study found that mice fed mackerel supplements exhibited a $28 \%$ increase in brain DHA, as well as a longer response when it comes to staying in the dark room, than those fed an n-3 fatty acid deficient diet. Thus, the improved learning behavior exhibited by the mice fed with mackerel may be associated with an increase in the DHA found in nervous tissues, although our data were preliminary. These results suggest that mackerel dried by low temperature vacuum may represent a useful means of increasing the intake of these n-3 PUFAs.

\section{ACKNOWLEDGMENTS}

This research was supported by a grant (KRF-2005-204F00020) from the Women Scientists Program by the Korea Research Foundation, Republic of Korea.

\section{REFERENCES}

[1] He K, Song Y, Daviglus ML, et al. Accumulated evidence on fish consumption and coronary heart disease mortality: A meta-analysis of cohort studies. Circulation 2004; 109: 2705-2711.

[2] Ascherio A, Rimm EB, Stampfer MJ, Giovannucci EL, Willett WC. Dietary intake of marine n-3 fatty acids, fish intake, and the risk of coronary disease among men. N Engl J Med 1995; 332: 977-982.

[3] Siscovick DS, Raghunathan T, King I, et al. Dietary intake of longchain $\mathrm{n}-3$ polyunsaturated fatty acids and the risk of primary cardiac arrest. Am J Clin Nutr 2000; 71(Suppl. 1): 208S-212S.

[4] Kromhout D, Dosschieter EB, de Lezene Coulander C. The inverse relation between fish consumption and 20-year mortality from coronary heart disease. N Engl J Med 1985; 312: 1205-1209.

[5] Caicoya M. Fish consumption and stroke: a community case-control study in Austurias, Spain. Neuroepidemiology 2002; 21: 107114.

[6] Gochfeld M, Burger J. Good fish/bad fish: A composite benefitrisk by dose curve. Neurotoxicology 2005; 26: 511-520.

[7] Helland IB, Smith L, Saarem K, Saugstad OD, Drevon CA. Maternal supplementation with very-long-chain $n-3$ fatty acids during pregnancy and lactation augments children's IQ at 4 years of age. Pediatrics 2003; 111: e39-e44.

[8] Jarvik ME, Kopp R. An improved one-trial passive avoidance learning situation. Psychol reports 1967; 21: 221-224.

[9] Folch J, Lees M, Sloane-Stanley GH. A simple method for the isolation and purification of total lipids from animal tissues. J Biol Chem 1957; 226: 497-509.

[10] Morrison WR, Smith LM. Preparation of fatty acid methyl esters and dimethylacetals from lipids with boron fluoride-methanol. J Lipid Res 1964; 5: 600-608.

[11] Salem N, Reyzer M, Karanian J. Losses of arachidonic acid in rat liver after alcohol inhalation. Lipids 1996; 31: S153-S156

[12] Lim SY, Suzuki H. Dose-response effect docosahexaenoic acid ethyl ester on maze behavior and brain fatty acid composition in adult mice. Int J Vitam Nutr Res 2002; 72: 77-84.

[13] Suzuki H, Park SJ, Tamura M, Ando S. Effect of the long-term feeding of dietary lipids on the learning ability, fatty acid composition of brain stem phospholipids and synaptic membrane fluidity in adult mice: a comparison of sardine oil diet with palm oil diet. Mech Ageing Dev 1998; 101:119-128.

[14] Garcia-Calatayud S, Redondo C, Martin E, et al. Brain docosahexaenoic acid status and learning in young rats submitted to dietary long-chain polyunsaturated fatty acid deficiency and supplementation limited to lactation. Pediatr Res 2005; 57: 719-723.

[15] Gamoh S, Hashimoto M, Sugioka K, et al. Chronic administration of docosahexaenoic acid improves reference memory-related learning ability in young rats. Neuroscience 1999; 93: 237-241.

[16] Moriguchi T, Greiner RS, Salem N. Behavioral deficits associated with dietary induction of decreased brain docosaehxaenoic acid concentration. J Neurochem 2000; 75: 2563-2573.

[17] Frances H, Monier C, Clement M, et al. Effect of dietary alphalinolenic acid deficiency on habituation. Life Sci 1996; 58: 18051816.

[18] Zimmer L, Depal S, Guilloteau D, Aioun J, Durand G. Chronic n-3 polyunsaturated fatty acid deficiency alters dopamine vesicle density in the rat frontal cortex. Neurosci Lett 2000; 84: 25-28.

[19] Kamijin S, Launer LJ, Ott A, et al. Dietary fat intake and the risk of incident dementia in the Rotterdam study. Ann Neurol 1997; 42: 776-782.

[20] Hibbeln JR, Salem N. Dietary polyunsaturated fatty acids and depression: when cholesterol does not satisfy. Am J Clin Nutr 1995; 62: 1-9. 
[21] Suzuki H, Morikawa Y, Takahashi H. Effect of DHA oil supplementation on intelligence and visual acuity in the elderly. World Rev Nutr Diets 2001; 88: 68-71.

[22] Hamazaki T, Sawazaki S, Itomura M, et al. The effect of docosahexaenoic acid on aggression in young adults. A placebo-controlled double-blind study. J Clin Invest 1996; 97: 1129-1133.
[23] Lim GP, Calon F, Morihara T, et al. A diet enriched with the omega-3 fatty acid docosahexaenoic acid reduces amyloid burden in an aged Alzheimer mouse model. J Neurochem 1993; 60: 20182028.

(C) Lim and Choi; Licensee Bentham Open.

This is an open access article licensed under the terms of the Creative Commons Attribution Non-Commercial License (http://creativecommons.org/licenses/by$\mathrm{nc} / 3.0 /$ ) which permits unrestricted, non-commercial use, distribution and reproduction in any medium, provided the work is properly cited. 